\title{
Improved insulin sensitivity, preserved beta cell function and improved whole-body glucose metabolism after low-dose growth hormone replacement therapy in adults with severe growth hormone deficiency: a pilot study
}

\author{
A. M. Arafat • M. Möhlig • M. O. Weickert • C. Schöfl • \\ J. Spranger • A. F. H. Pfeiffer
}

Received: 1 November 2009 / Accepted: 2 March 2010/Published online: 6 April 2010

(C) Springer-Verlag 2010

\begin{abstract}
Aims/hypothesis Growth hormone-deficient patients show deterioration of insulin sensitivity and beta cell function. High-dose growth hormone treatment often induces further impairment of insulin sensitivity, leading to an increase in insulin and glucose levels or even, in cases of preexisting beta cell defect, to overt diabetes. However, low-dose treatment may improve insulin sensitivity, although data in humans with detailed metabolic phenotyping are as yet not
\end{abstract}

\footnotetext{
A. M. Arafat $(\bowtie) \cdot$ M. Möhlig $\cdot$ J. Spranger $\cdot$ A. F. H. Pfeiffer Department of Endocrinology, Diabetes and Nutrition, Charité-University Medicine Berlin, Campus Benjamin Franklin, Hindenburgdamm 30, 12200 Berlin, Germany

e-mail: ayman.arafat@charite.de
}

\begin{abstract}
A. M. Arafat · M. Möhlig • M. O. Weickert · J. Spranger ·
A. F. H. Pfeiffer

Department of Clinical Nutrition,

German Institute of Human Nutrition Potsdam-Rehbruecke,

Nuthetal, Germany
\end{abstract}

M. O. Weickert

Warwickshire Institute for the Study of Diabetes, Endocrinology, and Metabolism,

Coventry, UK

C. Schöfl

Division of Neuroendocrinology, Department of Neurosurgery, Friedrich-Alexander-University Erlangen-Nuremberg,

Erlangen, Germany

M. O. Weickert

Clinical Sciences Research Institute, Warwick Medical School, University of Warwick,

Coventry, UK available. We postulated that long-term low-dose growth hormone replacement, restoring IGF-1 to the low-normal range, might beneficially affect glucose metabolism.

Methods We studied prospectively the metabolic responses to 24 and 48 weeks of growth hormone treatment in a small group of six adults with severe growth hormone deficiency (four men, two women; age 40-59 years; BMI 30.2 \pm 1 $\mathrm{kg} / \mathrm{m}^{2}$; mean growth hormone dose $0.3 \pm 0.04 \mathrm{mg}$ /day). All participants underwent an oral glucose tolerance test, euglycaemic-hyperinsulinaemic clamp and hyperglycaemic-hyperinsulinaemic clamp plus i.v. L-arginine on three occasions. Insulin sensitivity was measured by calculating the $M$ value during the steady state of the euglycaemichyperinsulinaemic clamp. Insulin secretion and clearance were estimated from $\mathrm{AUC}_{\mathrm{C} \text {-peptide, }} \mathrm{AUC}_{\mathrm{insulin}}$ and their ratio at each phase of the hyperglycaemic-hyperinsulinaemic clamp.

Results Growth hormone significantly improved insulin sensitivity ( $M$ value $13.8 \pm 2.6$ [baseline] vs $19.6 \pm 2.6$ [24 weeks] and $23.7 \pm 1.9$ [48 weeks] $\mu \mathrm{mol} \mathrm{kg}{ }^{-1} \mathrm{~min}^{-1} ; p<$ 0.01 ). Although the insulin response to glucose and arginine decreased slightly, the disposition index, integrating insulin sensitivity and secretion, significantly increased $(p<0.01)$, indicating an improvement in whole-body glucose metabolism. Insulin clearance was not affected during treatment $(p>0.05)$.

Conclusions/interpretation Our data indicate that long-term low-dose growth hormone treatment may improve insulin sensitivity and whole-body glucose metabolism in adults with severe growth hormone-deficiency.

Trial registration: ClinicalTrials.gov NCT00929799

Funding: The study was supported by a research grant from Pfizer Inc. (NRA 6280012) 
Keywords Beta cell function - C-peptide .

Euglycaemic-hyperinsulinaemic clamp .

Growth hormone deficiency - Growth hormone replacement therapy $\cdot$ Hyperglycaemic clamp $\cdot$ Insulin .

Insulin clearance $\cdot$ Insulin sensitivity .

Oral glucose tolerance test

$\begin{array}{ll}\text { Abbreviations } \\ \text { ICI } & \text { Insulin clearance index } \\ \text { ISR } & \text { Insulin secretion rates } \\ \mathrm{MCR}_{\text {insulin }} & \text { Insulin metabolic clearance rates }\end{array}$

\section{Introduction}

Similarities between untreated adult growth hormone deficiency syndrome and the metabolic syndrome, including central obesity and insulin resistance [1], are proposed to play a major contributing role to the excess rate of cardiovascular morbidity and mortality in these patients $[2,3]$.

In adult patients with growth hormone deficiency, treatment with recombinant human growth hormone results in a reduction of visceral fat mass and an increase in lean body mass [4]. However, short- and long-term effects of growth hormone replacement on glucose metabolism are less consistent and have been proved to be dose-dependent. Regardless of dose, the insulin antagonistic effect of growth hormone during the initial phase of growth hormone treatment often induces an insulin-resistant state leading to increased insulin secretion or even, in cases with a preexisting beta cell defect, to overt diabetes [5-8]. Long-term studies, however, have reported discrepant findings. Thus long-term standard-dose growth hormone replacement (i.e. growth hormone doses titrated to normalise serum IGF-1 levels according to sex and age) led to persistent impairment of $[7,9]$ or no change in insulin sensitivity $[10,11]$. However, investigators using long-term low-dose growth hormone treatment reported gradual but persistent improvement in glucose metabolism in some [12, 13], but not all studies [14].

Growth hormone has been shown to stimulate pancreatic beta cell proliferation directly or via IGF-1 [15], which is considered to play an essential role in enhancing beta cell function [15-18] and in protecting beta cells from apoptosis [19] independently of growth hormone and most probably via the IGF-1 receptor on the beta cell.

However, existing studies are limited in that they used fasting insulin and glucose-based indices only, rather than the so called 'gold standard' methods, to estimate insulin sensitivity and secretion $[4,6]$. Thus, results from these studies do not necessarily reflect the precise phenotype, which may, therefore, account for the somewhat discrepant findings on changes in beta cell function in treated growth hormone-deficient adults $[4,6]$. Accurate estimation of beta cell function requires the consideration of insulin sensitivity, due to the well-known inverse relation between insulin sensitivity and insulin secretion along a hyperbolic curve [20]. Moreover, growth hormone has been postulated to decrease the insulin clearance [21, 22]. Hence, a comprehensive analysis of whole-body glucose metabolism should include a detailed and dynamic analysis of insulin secretion, insulin sensitivity and insulin clearance. Finally, these variables need to be integrated within one analytic model, such as the disposition index.

Using highly standardised techniques, we therefore performed detailed investigations of insulin sensitivity and beta cell function after 24 and 48 weeks of low-dose growth hormone therapy in a small group of adult patients with severe growth hormone deficiency. Insulin sensitivity was estimated using euglycaemic-hyperinsulinaemic clamps, while insulin secretion and hepatic insulin clearance were determined by changes in insulin and C-peptide levels during and hyperglycaemic-hyperinsulinaemic clamps with consecutive i.v. L-arginine stimulation tests. Finally, we investigated changes in body composition, lipolysis and cardiovascular risk markers.

\section{Methods}

Participants We prospectively investigated six consecutively recruited patients with severe growth hormone deficiency and at least one other pituitary hormone deficiency (four men, two women; age 40-59 years; BMI $30.2 \pm 1 \mathrm{~kg} / \mathrm{m}^{2}$ ) (Table 1). Four of these patients had clinically nonfunctioning pituitary macroadenomas that were removed via transsphenoidal surgery; the other two had traumatic brain injury. All patients were on stable replacement therapy with thyroid hormone, hydrocortisone, gonadal steroids or desmopressin as appropriate. None of the patients had been on growth hormone replacement therapy before the study was started. Severe growth hormone deficiency was diagnosed by an inadequate growth hormone stimulation in three tests (peak response $<3 \mu \mathrm{g} / 1$ during insulin tolerance test, $<3 \mu \mathrm{g} / \mathrm{l}$ during glucagon test and $<9 \mu \mathrm{g} / \mathrm{l}$ during growth hormone-releasing hormone-arginine test).

The major exclusion criteria included: history of diabetes mellitus, biochemical evidence of impaired hepatic or renal function, history of cardiovascular disease, uncontrolled hypertension, any current inflammatory or malignant disease, and pregnancy.

The study protocol was approved by the Ethical Committee of Charite University Medicine Berlin and performed according to the requirements of the Declaration of Helsinki. Written informed consent was obtained from all participants.

The pre-defined primary endpoint was change of baseline insulin sensitivity after 24 and 48 weeks of treatment with 
Table 1 Primary diagnosis, primary therapy and hormone replacement therapy in the study population of six patients

\begin{tabular}{|c|c|c|c|c|c|c|c|c|c|}
\hline Age (years) & Sex & Weight (kg) & Waist (cm) & Diagnosis & Primary therapy & $\mathrm{HC}$ & $\mathrm{T} 4$ & Sex steroids & dDAVP \\
\hline 59.0 & M & 91 & 96 & NFPA & TSS & + & + & + & - \\
\hline 53.0 & M & 88.5 & 95 & TBI & TSS & + & - & - & - \\
\hline 55.0 & $\mathrm{~F}$ & 82 & 102 & NFPA & - & + & + & - & - \\
\hline 55.0 & M & 124 & 124 & NFPA & TSS & - & - & + & - \\
\hline 40.0 & M & 113 & 121 & TBI & - & - & + & + & + \\
\hline 45.0 & $\mathrm{~F}$ & 78 & 95 & NFPA & TSS & - & + & + & - \\
\hline
\end{tabular}

dDAVP, desmopressin; F, female; HC, hydrocortisone; M, male; NFPA, clinically non-functioning pituitary adenoma; T4, thyroid hormone; TBI, traumatic brain injury; TSS, transphenoidal surgery

low growth hormone dose in severely growth hormonedeficient patients. Secondary endpoints included changes in insulin secretion and insulin clearance vs baseline, as well as changes in body composition, lipolysis and cardiovascular risk markers (also vs baseline).

Study procedures All participants attended clinical assessments at baseline, and after 24 and 48 weeks of growth hormone treatment. At each of the three visits, patients underwent an oral glucose tolerance test, euglycaemic-hyperinsulinaemic clamp and hyperglycaemic-hyperinsulinaemic clamp with consecutive i.v. L-arginine stimulation test.

A full medical history was obtained at baseline, followed by physical examination and recording of height, weight and both waist and hip circumference for assessment of BMI and WHR. Body composition was estimated in the supine position by bioelectric impedance analysis (BIA101-S; RJL-Systems, Detroit, MI, USA). A $50 \mathrm{kHz}, 800 \mathrm{~mA}$ current was applied.

Patients were taught to self-administer recombinant human growth hormone (1 mg is equivalent to $3 \mathrm{IU}$; Genotropin, Pfizer Inc., New York, USA) in the abdominal subcutaneous tissue using a Genotropin pen at 22:00 hours every day. All patients were assigned to a maximal growth hormone dose of $0.003 \mathrm{mg} \mathrm{kg}^{-1} \mathrm{day}^{-1}$ to avoid growth hormone-induced lipolysis [23]. Growth hormone dose was down-titrated after 4 weeks to keep serum IGF-1 concentrations below the 50th percentile for the respective age-related range. From months 1 to 12 the patients were maintained at a mean dose of $0.3 \pm$ $0.004 \mathrm{mg} /$ day. A study period of 12 months was chosen to avoid transient changes in insulin resistance [24]. During the study, patients were asked to maintain their usual diet and physical activity, and to report if they were started on any new medications.

To adjust for the influence of gonadal steroids on insulin sensitivity $[25,26]$, study procedures were performed with the same time interval after a given injection of testosterone in men; in women procedures were performed in the same phase of gonadal hormone substitution.

Following an overnight fast, OGTT was performed at each visit as previously described [27].
Participants were then investigated on separate days for assessment of whole-body glucose disposal using euglycaemic-hyperinsulinaemic clamps as detailed previously [28]. Clamps were performed for at least $2 \mathrm{~h}$ using $40 \mathrm{mIU} \mathrm{m} \mathrm{min}^{-1}$ human insulin (Actrapid; Novo Nordisk, Bagsvaard, Denmark) and a variable infusion of $100 \mathrm{~g} / \mathrm{l}$ glucose (Serag Wiessner, Naila, Germany). Capillary glucose concentrations were monitored every $5 \mathrm{~min}$ and levels were maintained between 4.0 and $4.9 \mathrm{mmol} / \mathrm{l}$. In the steady-state condition of the clamp (last $30 \mathrm{~min}$ ) plasma glucose was adjusted to $4.4 \mathrm{mmol} / \mathrm{l}$. Glucose was measured in urine samples obtained at the end of the clamp to exclude urinary losses. All infusions were administered into an antecubital vein, while blood samples for analysis were drawn from an antecubital vein at the contralateral arm at baseline and during steady state of the euglycaemic-hyperinsulinaemic clamp. Plasma potassium concentrations were controlled before and during the clamp to avoid insulin-induced hypokalaemia. Potassium substitution was not necessary in this study.

On a third occasion, the patients underwent a hyperglycaemic-hyperinsulinaemic clamp with consecutive i.v. L-arginine stimulation test for assessment of insulin secretion and clearance $[20,29,30]$. In the morning, after a $12 \mathrm{~h}$ fast, a distal forearm vein was punctured with a Teflon cannula (Moskito 123, 18 g; Vygon, Aachen, Germany) in a retrograde fashion for drawing of blood samples. At the same time, an antecubital vein of the contralateral arm was cannulated for infusions. Participants were studied in the supine position with the hand warmed to 60 to $70^{\circ} \mathrm{C}$ using a heating pad to obtain arterialised venous blood. Both ear lobes were made hyperaemic using Finalgon $(4 \mathrm{mg} / \mathrm{g}$ nonivamid, $25 \mathrm{mg} / \mathrm{g}$ nicoboxil). After baseline samples had been obtained, an intravenous bolus of $200 \mathrm{~g} / \mathrm{l}$ glucose was given over $2 \mathrm{~min}$ to instantaneously raise capillary blood glucose to $8.9 \mathrm{mmol} / \mathrm{l}$ (glucose bolus calculated as body weight in $\mathrm{kg} \times 0.3 \mathrm{~g}$ glucose). Capillary blood glucose concentrations (from a hyperaemic ear lobe) were determined at bedside every $5 \mathrm{~min}$. Subsequently, the glucose infusion was adjusted to maintain capillary blood 
glucose at $8.9 \mathrm{mmol} / 1$ (to avoid urinary excretion of glucose) for $2 \mathrm{~h}$. At $90 \mathrm{~min}$, a $5 \mathrm{~g}$ bolus (12\% of infusion dose) of arginine (L-arginine hydrochloride $4.214 \mathrm{~g}$ in $20 \mathrm{ml}$ water; Braun, Melsungen, Germany) and a continuous infusion $\left.(10 \mathrm{mg} \text { [kg body weight }]^{-1} \mathrm{~min}^{-1}\right)$ of arginine were given for the next $30 \mathrm{~min}$. Blood samples for insulin and C-peptide measurement were taken at $-10,-5,0,2,3,4,5$, $7.5,10,15,20,25,30,40,50,60,70,80,90,92.5,95$, $97.5,100,105,110,115$ and $120 \mathrm{~min}$. Plasma and serum were kept frozen until assayed.

Hormone assays Capillary blood glucose and serum insulin concentrations were measured as described previously [27].

Serum C-peptide levels were measured by ELISA (Mercodia, Uppsala, Sweden), with negligible crossreaction with insulin $(<0.001 \%)$ and proinsulin $(<1.8 \%)$. Intra- and interassay coefficients of variation were $5 \%$. The sensitivity limit was $15 \mathrm{pmol} / \mathrm{l}$.

Serum cholesterol, triacylglycerol, HDL-cholesterol, LDL-cholesterol and C-reactive protein were measured by standard procedures.

Nonesterified fatty acids were quantified in serum using a commercially available assay (NEFA C; Wako, Neuss, Germany) performed on Cobas Mira (Roche, Basel, Switzerland). The intra- and interassay coefficients of variation were $<5 \%$ and $4.7 \%$ respectively.

Serum IGF-1 was measured as described previously [27]. Normal IGF-1 range was 109 to $284 \mu \mathrm{g} / \mathrm{l}, 101$ to $267 \mu \mathrm{g} / 1,87$ to $238 \mu \mathrm{g} / \mathrm{l}$ and 81 to $225 \mu \mathrm{g} / \mathrm{l}$ in $36-$ to $40-$, 41- to 45-, 51- to 55- and 56- to 60-year-old participants respectively [31].

Calculations Fasting measurements of glucose, insulin and C-peptide were calculated as the mean of the $0,-5$ and -10 min values.

Insulin sensitivity was measured by calculating the $M$ value during the steady state of the euglycaemichyperinsulinaemic clamp using the glucose infusion rate during steady state $(\mu \mathrm{mol} / \mathrm{min})$ divided by body weight (kg) [30].

The hyperglycaemic-hyperinsulinaemic clamp was divided into the following phases: basal phase $(-10,-5$ and $0 \mathrm{~min})$, first-phase response to glucose $(0-10 \mathrm{~min})$, second-phase response to glucose (30-60 $\mathrm{min}$ ) and acute response to arginine phase (90-100 $\mathrm{min}$ ). Insulin secretion and clearance were assessed by calculating [30] the following: (1) firstphase insulin response to glucose and first-phase C-peptide response to glucose: average of measured insulin or C-peptide concentrations during first phase; (2) second-phase insulin response to glucose and second-phase C-peptide response to glucose: average of measured insulin or C-peptide concentrations during second phase; (3) acute insulin response to arginine and acute $\mathrm{C}$-peptide response to arginine: maximal insulin or C-peptide concentrations during acute response to arginine phase after subtracting baseline ( $90 \mathrm{~min}$ ) concentration; (4) insulin-AUC $\mathrm{Atime}_{\text {and }} \mathrm{C}$-peptide-AUC $\mathrm{C}_{\text {time: }}$ : incremental area under the insulin or C-peptide curve that was measured using the trapezoidal rule during each clamp

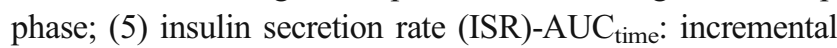
area under the curve of the pre-hepatic ISR that was calculated using a two-compartment model of C-peptide kinetics (deconvolution method) [32,33] during each clamp phase; (6) insulin metabolic clearance rate $\left(\mathrm{MCR}_{\text {insulin }}\right)$ : ratio of ISR-AUC:insulin-AUC during the basal phase [33]; (7) insulin clearance index (ICI) over time: calculated from the ratio of C-peptide-AUC $C_{\text {time:insulin-AUC }}$ time during each clamp phase [32, 34]; and (8) disposition index: calculated as index that integrates insulin sensitivity and secretion [20, 34] by multiplying the $M$ value and C-peptide-AUC $\mathrm{C}_{\text {time }}$ during each clamp phase.

Statistical analyses Statistical analyses were performed using SPSS version 16 (SPSS, Chicago, IL, USA). All data are expressed as means \pm SEM, unless stated otherwise. We used ANOVA for repeated measures to analyse the effect of 24 and 48 weeks of growth hormone treatment on variables for anthropometry, body composition, insulin sensitivity, insulin secretion, insulin clearance, cardiovascular risk factors and other biochemical variables. Skewed data were logtransformed to obtain normal distribution. The Shapiro-Wilk test was used to test for normal distribution. When ANOVA was significant, serial changes were compared with baseline using Student's $t$ test for paired analysis in case of normally distributed data. For skewed data, the non-parametric Wilcoxon test was used. All significances are two-sided and values of $p<0.05$ were regarded as statistically significant. Associations between variables were assessed by calculating Spearman correlation coefficients for skewed data and Pearson correlation coefficients for normally distributed data.

\section{Results}

Baseline characteristics and anthropometric changes of study participants Baseline characteristics of the study participants are shown in Table 1. At baseline, all patients had a subnormal serum IGF-1 concentration, which increased significantly during growth hormone treatment (Table 2). At the end of the study, serum IGF-1 levels were below the 50th percentile for the respective age-related range [31]. According to the new International Diabetes Federation criteria for metabolic syndrome [35], all patients had an increased waist circumference. No significant changes in BMI, body composition, waist circumference and WHR measurements were observed following 24 weeks or 48 weeks of growth hormone treatment (Table 2). 
Table 2 Changes in anthropometry, body composition, biochemical variables and cardiovascular risk markers after 24 and 48 weeks of growth hormone treatment in patients with severe growth hormone deficiency
Values are presented as mean \pm SEM

${ }^{\mathrm{a}} p<0.05$ was considered as statistically significant;

${ }^{\mathrm{b}}$ during OGTT

\begin{tabular}{|c|c|c|c|c|}
\hline Variable & Baseline & 24 weeks & 48 weeks & $p$ value $^{\mathrm{a}}$ \\
\hline \multicolumn{5}{|l|}{ Anthropometry } \\
\hline $\operatorname{BMI}\left(\mathrm{kg} / \mathrm{m}^{2}\right)$ & $30.2 \pm 1.0$ & $31.0 \pm 1.1$ & $29.4 \pm 1.9$ & NS \\
\hline Waist circumference $(\mathrm{cm})$ & $105.5 \pm 5.5$ & $104.2 \pm 4.9$ & $100.2 \pm 7.2$ & NS \\
\hline WHR & $0.99 \pm 0.04$ & $0.97 \pm 0.02$ & $0.95 \pm 0.04$ & NS \\
\hline \multicolumn{5}{|l|}{ Body composition } \\
\hline Truncal fat mass $(\mathrm{kg})$ & $24.8 \pm 3.2$ & $26.4 \pm 4.1$ & $23.8 \pm 3.8$ & NS \\
\hline Truncal lean mass (kg) & $69.9 \pm 8.9$ & $68.2 \pm 8.4$ & $68.7 \pm 7.9$ & NS \\
\hline \multicolumn{5}{|l|}{ Biochemical variables } \\
\hline Creatinine $(\mu \mathrm{mol} / \mathrm{l})$ & $88.9 \pm 6.16$ & $86.7 \pm 7.9$ & $88.9 \pm 9.69$ & NS \\
\hline Uric acid $(\mu \mathrm{mol} / \mathrm{l})$ & $381 \pm 20.73$ & $391.3 \pm 23.2$ & $393.5 \pm 24.3$ & NS \\
\hline Protein $(g / 1)$ & $67.5 \pm 2.97$ & $67.3 \pm 2.2$ & $65.7 \pm 3.4$ & NS \\
\hline IGF-1 $(\mu \mathrm{g} / \mathrm{l})$ & $86.2 \pm 5.1$ & $154.8 \pm 9.3$ & $148.7 \pm 6.3$ & $<0.05$ \\
\hline Fasting glucose $(\mathrm{mmol} / \mathrm{l})$ & $5.6 \pm 0.4$ & $5.4 \pm 0.4$ & $5.5 \pm 0.3$ & NS \\
\hline Fasting insulin (pmol/1) & $98.9 \pm 26.1$ & $91.4 \pm 25$ & $85.7 \pm 37.4$ & NS \\
\hline Fasting C-peptide (pmol/1) & $1,161 \pm 193$ & $1,090 \pm 168$ & $860 \pm 264$ & NS \\
\hline $120 \mathrm{~min}$ glucose $(\mathrm{mmol} / \mathrm{l})^{\mathrm{b}}$ & $7.9 \pm 0.6$ & $6.3 \pm 0.4$ & $6.5 \pm 0.5$ & $<0.05$ \\
\hline NEFA (mmol/l) & $0.55 \pm 0.11$ & $0.46 \pm 0.07$ & $0.30 \pm 0.03$ & NS \\
\hline \multicolumn{5}{|l|}{ Cardiovascular risk markers } \\
\hline Total cholesterol $(\mathrm{mmol} / \mathrm{l})$ & $5.56 \pm 0.43$ & $5.80 \pm 0.68$ & $6.27 \pm 0.66$ & NS \\
\hline HDL-cholesterol (mmol/l) & $1.14 \pm 0.20$ & $1.20 \pm 0.24$ & $1.29 \pm 0.19$ & $<0.05$ \\
\hline LDL-cholesterol (mmol/l) & $3.07 \pm 0.32$ & $3.51 \pm 0.38$ & $3.74 \pm 0.47$ & NS \\
\hline Triacylglycerol (mmol/1) & $2.99 \pm 0.61$ & $2.41 \pm 0.43$ & $2.72 \pm 0.35$ & NS \\
\hline C-reactive protein $(\mathrm{mg} / \mathrm{l})$ & $2.75 \pm 1.65$ & $1.72 \pm 0.78$ & $2.10 \pm 1.13$ & NS \\
\hline
\end{tabular}

Changes in insulin sensitivity Growth hormone successively and dramatically improved insulin sensitivity after 24 and 48 weeks of treatment ( $M$ value baseline $13.8 \pm 2.6$ vs $19.6 \pm$ 2.6 and $23.7 \pm 1.9 \mu \mathrm{mol} \mathrm{kg}{ }^{-1} \min ^{-1}$ at 24 and 48 weeks, respectively; $p<0.01$ ) (Fig. 1).

Insulin concentrations during steady state were comparable between the baseline clamps $(509.9 \pm 53.1 \mathrm{pmol} / 1)$ and the follow-up clamps at $24(525.98 \pm 34.2, p=0.75)$ and 48 (560.1 $\pm 61.9, p=0.17)$ weeks of growth hormone treatment.

Relative changes in IGF-1 concentrations were positively correlated with relative changes in insulin sensitivity

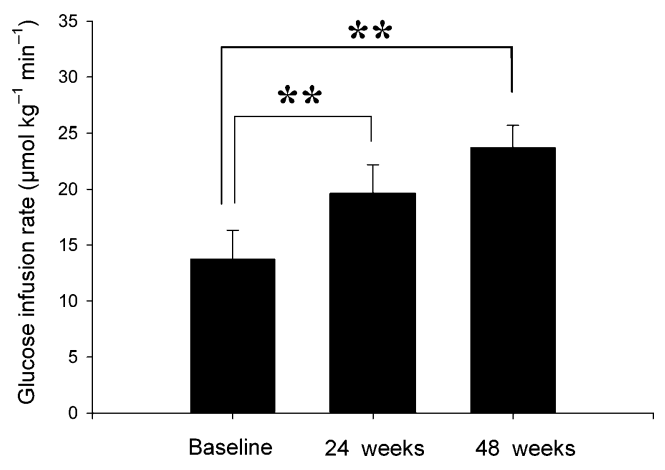

Fig. 1 Changes in insulin sensitivity ( $M$ value) after 24 and 48 weeks of low-dose growth hormone treatment in patients with severe growth hormone deficiency. $* * p<0.01$ measurements ( $M$ values) obtained after 24 and 48 weeks of growth hormone treatment $(r=0.579, p=0.024)$.

Changes in insulin secretion and insulin clearance The $\mathrm{MCR}_{\text {insulin }}$ and the ICI, which were estimated at each clamp period, remained unchanged during growth hormone treatment $(p=0.4$ to $p=0.9)$ (Table 3 ).

However, the first and second insulin and C-peptide responses to glucose as well as insulin responses to arginine decreased during growth hormone treatment (Table 3) as may be expected if these adapt metabolically to changes in insulin sensitivity. Similarly, the incremental area under the ISR curve during the first (ISR-AUC ${ }_{0-10}$ ) and second responses (ISR-AUC $\mathrm{AU}_{30-90}$ ) to glucose as well as insulin responses to arginine (ISR-AUC ${ }_{90-100}$ ) decreased after growth hormone treatment (Table 3).

Basal C-peptide concentration, its first and second phase response to glucose, as well as its response to arginine stimulation, were inversely correlated with insulin sensitivity (Fig. 2), supporting the notion that reduced secretion is likely to be compensatory in face of improved insulin sensitivity.

The disposition index To integrate the alterations of insulin sensitivity and secretion in a comprehensive model of glucose metabolism, the disposition index was calculated 
Table 3 Changes in insulin secretion and clearance after 24 and 48 weeks of growth hormone treatment in patients with severe growth hormone deficiency

\begin{tabular}{|c|c|c|c|}
\hline Variable & Baseline & 24 weeks & 48 weeks \\
\hline FIR (pmol/l) & $463.8 \pm 152$ & $288.3 \pm 78^{*}$ & $233.5 \pm 70^{*}$ \\
\hline SIR (pmol/l) & $547.3 \pm 211$ & $396.8 \pm 103 *$ & $319.5 \pm 88^{*}$ \\
\hline AIR (pmol/l) & $3,234.9 \pm 841$ & $2,826.1 \pm 723^{*}$ & $2,207.9 \pm 500^{*}$ \\
\hline FCPR (pmol/l) & $2,238.4 \pm 389$ & $1,714.9 \pm 252^{*}$ & $1,354 \cdot 2 \pm 345^{*}$ \\
\hline SCPR (pmol/l) & $3,082.1 \pm 491$ & $2,542.2 \pm 334^{*}$ & $2,134.5 \pm 513^{*}$ \\
\hline ACPR (pmol/l) & $6,762.8 \pm 785$ & $5,607.1 \pm 661 *$ & $3,605.1 \pm 627 *$ \\
\hline Insulin-AUC $\mathrm{A}_{0-10 \min }\left(\mathrm{pmol}^{-1} \mathrm{~min}^{-1}\right)$ & $5,606 \pm 1,982$ & $3,554 \pm 1,039 *$ & $2,783 \pm 869^{*}$ \\
\hline Insulin-AUC ${ }_{30-90 \min }\left(\mathrm{pmol} \mathrm{l}^{-1} \mathrm{~min}^{-1}\right)$ & $33,059 \pm 12,828$ & $22,930 \pm 6,306^{*}$ & $18,846 \pm 5,091^{*}$ \\
\hline Insulin-AUC $90-100 \min \left(\mathrm{pmol} \mathrm{l}^{-1} \mathrm{~min}^{-1}\right)$ & $21,666 \pm 6,895$ & $14,561 \pm 3,884 *$ & $14,443 \pm 3,650^{*}$ \\
\hline C-peptide-AUC ${ }_{0-10 \min }\left(\mathrm{pmol} \mathrm{l}^{-1} \min ^{-1}\right)$ & $22,796 \pm 4,060$ & $17,344 \pm 2,555^{*}$ & $9,765 \pm 2,890^{*}$ \\
\hline C-peptide-AUC ${ }_{30-90 \min }\left(\mathrm{pmol} \mathrm{l}^{-1} \mathrm{~min}^{-1}\right)$ & $192,634 \pm 28,387$ & $151,604 \pm 19,295^{*}$ & $127,340 \pm 30,749^{*}$ \\
\hline C-peptide-AUC $C_{90-100 \min }\left(\mathrm{pmol} \mathrm{l}^{-1} \min ^{-1}\right)$ & $64,113 \pm 10,821$ & $49,115 \pm 6,870^{*}$ & $43,071 \pm 9,007^{*}$ \\
\hline $\mathrm{ISR} \mathrm{AUC} \mathrm{C}_{0-10} \min (\mathrm{pmol})$ & $14,932 \pm 4,549$ & $12,524 \pm 3,489^{*}$ & $9,992 \pm 2,920 *$ \\
\hline $\mathrm{ISR}-\mathrm{AUC}_{30-90 \min }(\mathrm{pmol})$ & $59,944 \pm 9,292$ & $47,560 \pm 7,329 *$ & $46,487 \pm 11,440^{*}$ \\
\hline $\mathrm{ISR}_{-} \mathrm{AUC} \mathrm{C}_{90-100 \mathrm{~min}}(\mathrm{pmol})$ & $59,762 \pm 12,137$ & $45,895 \pm 13,639^{*}$ & $35,297 \pm 10,564^{*}$ \\
\hline $\operatorname{MCR}_{\text {insulin }}(1 / \mathrm{min})$ & $3.96 \pm 1.2$ & $4.1 \pm 0.8$ & $4.5 \pm 0.9$ \\
\hline $\mathrm{ICI}_{\text {Basal }}$ & $13.08 \pm 1.25$ & $13.64 \pm 1.47$ & $12.58 \pm 2.33$ \\
\hline $\mathrm{ICI}_{0-10 \min }$ & $5.58 \pm 1.3$ & $6.83 \pm 1.8$ & $6.46 \pm 1.78$ \\
\hline $\mathrm{ICI}_{30-90 \mathrm{~min}}$ & $7.73 \pm 1.1$ & $7.92 \pm 1.2$ & $7.63 \pm 1.3$ \\
\hline $\mathrm{ICI}_{90-100 \mathrm{~min}}$ & $3.50 \pm 0.4$ & $3.85 \pm 0.5$ & $3.19 \pm 0.35$ \\
\hline
\end{tabular}

Values are presented as mean $\pm \mathrm{SEM} ;{ }^{*} p<0.05$

ACPR, acute C-peptide response to arginine; AIR, acute insulin response to arginine; FCPR, first-phase C-peptide response to glucose; FIR, firstphase insulin response to glucose; SCPR, second-phase C-peptide response to glucose; SIR, second-phase insulin response to glucose

for each of the clamp periods. As shown in Fig. 3, the disposition index increased significantly $(p<0.01)$, indicating a potential improvement in whole-body glucose metabolism and at least preservation of beta cell function.

Relative changes in IGF-1 concentrations were positively correlated with relative changes in the disposition index measurements obtained after 24 and 48 weeks of growth hormone treatment ( $r=0.54$ to $r=0.611, p=0.017$ to $p=0.035$ ).

\section{Changes in metabolic profile, NEFA levels and cardiovascular} risk markers NEFA did not change significantly after growth hormone treatment (baseline $0.55 \pm 0.11 \mathrm{mmol} / 1 \mathrm{vs}$ $0.46 \pm 0.07$ and $0.30 \pm 0.03$ at 24 and 48 weeks, $p=0.43$ and $p=0.094$, respectively). However, we did observe a trend towards reduced baseline NEFA concentrations, albeit only after 48 weeks of treatment; this may be explained by the observed improvement in insulin sensitivity.

Similarly, low-dose growth hormone treatment did not significantly modify fasting glucose, fasting insulin, fasting C-peptide, total cholesterol, LDL-cholesterol, triacylglycerol or C-reactive protein levels (Table 2). However, following oral glucose intake, post-load glucose tolerance improved. Blood glucose levels decreased at 120 min compared with pre-treatment values $(p<0.05)$ (Table 2). At baseline, two patients had normal glucose tolerance and four had impaired glucose tolerance. After 24 weeks of treatment all patients had normal glucose tolerance. After 48 weeks, five patients had normal and one had impaired glucose tolerance. Similarly, HDL-cholesterol levels improved significantly after 24 and 48 weeks of growth hormone treatment (Table 2).

\section{Discussion}

We present novel data showing that long-term, low-dose growth hormone treatment $\left(0.003 \mathrm{mg} \mathrm{kg}^{-1}\right.$ day $\left.^{-1}\right)$ improves insulin sensitivity, preserves beta cell function and improves whole-body glucose metabolism without affecting body composition or inducing lipolysis in severely growth hormone-deficient adults. We postulate that these effects are mediated by the ability of low-dose growth hormone treatment to increase IGF-1 bioavailability in the absence of unfavourable lipolytic effects as observed in higher dose growth hormone replacement [36, 37].

Potential diabetogenic properties of growth hormone were first described in the 1930s, when Biasotti and Houssay reported that hypophysectomy reduced hyperglycaemia in a 

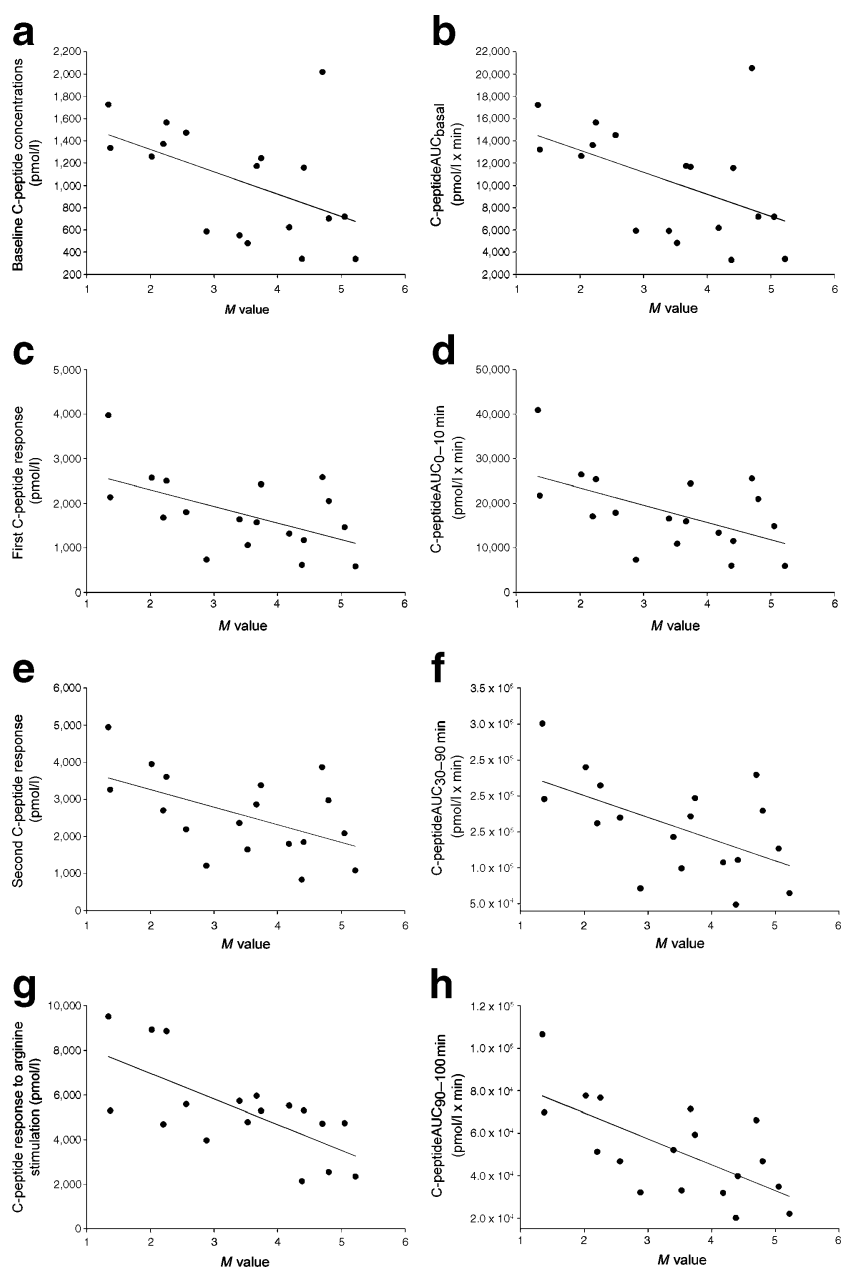

Fig. 2 The correlation between insulin sensitivity ( $M$ value) and insulin secretion as estimated by measuring the C-peptide responses at each phase of the hyperglycaemic-hyperinsulinaemic clamp. a $M$ value vs baseline C-peptide concentrations and (b) $M$ value vs C-peptideAUC $\mathrm{basal}(r=-0.5, p<0.05)$. c $M$ value vs first C-peptide response to glucose (mean $0-10 \mathrm{~min}$ ) and (d) $M$ value vs C-peptideAUC ${ }_{0-10}$ min $(r=-0.5, p<0.05)$. e $M$ value vs second C-peptide response to glucose (mean 30-90 min) and (f) $M$ value vs C-peptideAUC ${ }_{30-90}$ min $(r=-0.47, p<0.05)$. g $M$ value vs C-peptide response to arginine (maximum $90-100 \mathrm{~min}$ ) and (h) $M$ value vs C-peptideAUC ${ }_{90-100 ~ \min }(r=-0.6, p<0.05)$. All baseline and follow-up clamps measurements are included in each correlation

dog model of experimental diabetes [38]. Further studies demonstrated that the insulin-antagonistic effects of growth hormone are characterised by an increase in hepatic gluconeogenesis and glycogenolysis, and a decrease in peripheral glucose utilisation [39]. Other studies demonstrated that the predominant insulin antagonistic effect of growth hormone replacement derives from its lipolytic activity [36], since pharmacological inhibition of lipolytic actions of growth hormone restored [40] or even enhanced insulin sensitivity [41]. However, growth hormone-induced lipolysis has been shown to be dose-dependent, with the lowest growth hormone dose reported to induce lipolysis being $3 \cdot 3 \mu \mathrm{g} \mathrm{kg}^{-1}$ day $^{-1}[12,23,37]$, a dose that is higher than that chosen in our study. In agreement with this, the preservation of NEFA levels and fat body mass in the present study suggests that our low growth hormone dose did not induce lipolysis. This is also supported by previously published studies investigating low-dose growth hormone treatment in growth hormone deficiency patients and in healthy participants [12, 42]. By contrast, IGF-1, which is primarily synthesised by the liver following growth hormone stimulation, has been shown to demonstrate insulin-like effects, probably via the insulin-IGF-1 hybrid receptor [7]. Moreover, treatment with recombinant IGF-1 has consistently been shown to improve insulin sensitivity [7]. In the present study, changes in IGF-1 concentrations were positively associated with changes in measurements of insulin sensitivity. From these observations, it is tempting to speculate that the growth hormoneinduced improvement in insulin sensitivity is mediated through an increase in IGF-1 bioavailability in the absence of the opposing lipolytic and direct insulin-antagonistic effects of higher growth hormone doses.

The important association of central adiposity with insulin resistance is widely accepted. By contrast, we found that low-dose growth hormone treatment enhanced insulin sensitivity without modifying body composition, implying that central adiposity may not be the sole contributory factor to the development of insuln resistance in patients with growth hormone disorders. This concept is further supported by studies examining acromegaly patients, in whom increased central adiposity is not a prominent feature, despite the presence of insulin resistance [43]. Additionally, the administration of growth hormone receptor antagonist to those patients improved insulin sensitivity despite an increase in intra-abdominal fat [43].

Growth hormone exerts direct insulinotrophic effects on the beta cell [44-46]. High-dose growth hormone treatment increases insulin secretion associated with the early development of insulin resistance [46, 47], whereas prolonged administration of growth hormone in high doses results in reduced insulin secretion despite increasing insulin resistance, leading to deteriorating glucose tolerance [47]. These data indicate that chronic supraphysiological doses of growth hormone accelerate insulin resistance, compensatory hyperinsulinaemia and subsequent beta cell failure, a feature resembling the long-term sequelae of altered glucose homeostasis in untreated acromegalic patients.

By contrast, other studies have demonstrated the importance of IGF-1 in enhancing beta cell function $[15,16]$ and protecting beta cells from apoptosis [19]. Indirect evidence implicating IGF-1 in the enhancement of beta cell function has also been reported from studies of knockout mice lacking the beta cell IGF-1 receptor; these studies demonstrate defective glucose-stimulated insulin secretion and 

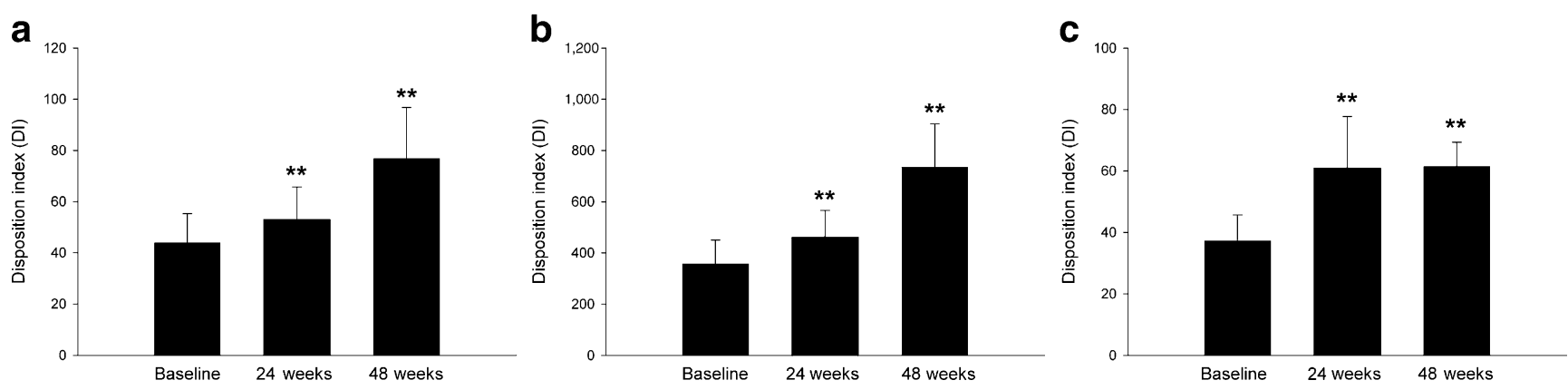

Fig. 3 Changes in disposition index (calculated by multiplying the $M$ value by the incremental area under the C-peptide curve measured with respect to the pre-stimulus concentrations at each phase of the hyperglycaemic-hyperinsulinaemic clamp). a First-phase response to glucose (0-10 $\mathrm{min})$. b Second-phase response to glucose (30-90 min). c Acute response to arginine stimulation (90-100 $\mathrm{min}$ ). Results are for 24 weeks and 48 weeks of low-dose growth hormone treatment in patients with severe growth hormone deficiency. $* * p<0.01$ glucose intolerance $[17,18]$. Considering that impaired beta cell function in face of decreased insulin sensitivity plays a crucial role in the pathogenesis of glucose intolerance [48], it can be postulated that low IGF-1 in untreated growth hormone deficiency is a major determinant of impaired beta cell function and glucose intolerance in these patients. The inverse curvilinear relation between insulin sensitivity and insulin secretion implies not only that insulin secretion is increased in insulin resistance, but also that increased insulin sensitivity is compensated by reduced insulin secretion [20]. The main outcome in this study, however, was that despite an adaptive reduction in insulin secretion, the improved insulin sensitivity observed in our patients was associated with an improvement in disposition index and, hence, in whole-body glucose metabolism. Moreover, changes in IGF-1 concentrations in the present study were positively associated with the changes in the disposition index. Taken together, this suggests that the increase in bioavailability of IGF-1 after lowdose growth hormone treatment accounts for the observed preservation of beta cell function and for the improvement in whole-body glucose metabolism. Nevertheless, the hyperbolic assumption could not be verified in the present study due to the small number of participants studied. Moreover, data shown in Fig. 2 are more suggestive of a normal adaptive response of insulin secretion to improved insulin sensitivity. Hence, although an improvement occurred, our data are more likely to be indicative of preservation of beta cell function.

In the present study, we also examined C-peptide, besides insulin, to investigate whether compensatory changes in insulin response in participants with increased insulin sensitivity may be entirely explained by changes in insulin secretion or whether altered clearance of endogenous insulin also contributes to this process. C-peptide is not extracted by the liver during its first passage, whereas insulin is extracted to a considerable degree $[20,32]$. Hence, the ratio of C-peptide to insulin can give an estimation of insulin clearance. In our study, insulin clearance measures $\left(\mathrm{MCR}_{\text {insulin }}\right.$ and $\left.\mathrm{ICI}_{\text {time }}\right)$ did not change significantly after growth hormone treatment.
Hence, the reduced insulin response following glucose and arginine challenges can be entirely explained by the compensatory reduction in insulin secretion.

Finally, along with previous studies [49], we observed that low-dose growth hormone treatment induced a moderate but significant increase in HDL-cholesterol levels without affecting total and LDL-cholesterol, triacylglycerol and C-reactive protein levels.

We previously showed that healthy women have significantly higher baseline and post-OGTT nadir growth hormone concentrations than men [27]. Hence, it can be assumed that sex may have an impact on growth hormoneinduced changes in glucose metabolism. However, insulin sensitivity and disposition index improved in all patients and changes were comparable in both sexes $(p>0.05)$. Moreover, inclusion of sex as a covariate in the ANOVA model revealed that it had no impact on treatment-induced effects. Nevertheless, due to the small number of participants included in our pilot study (two women, four men), an impact of sex on growth hormone-induced changes in glucose metabolism cannot be ruled out.

The present study has some noteworthy limitations. For example, it was an unblinded single-centre trial without a placebo-treated group and with a relatively low number of participants. However, we are the first to provide long-term data on the effects of low-dose growth hormone replacement in such patients, derived from the investigation of unselected patients and the use of accepted 'gold standard' methods for measurement of insulin sensitivity. Future, randomised, controlled trials should investigate whether the findings observed here can be replicated in larger cohorts. However, the striking and statistically significant differences between groups indicate that the effects of low-dose growth hormone treatment on glucose metabolism are substantial and clinically relevant.

Another limitation is that suppression of hepatic glucose production during euglycaemic-hyperinsulinaemic clamps can be overestimated and glucose rate of disappearance can 
be underestimated in insulin resistance [50], as in our growth hormone deficiency patients before growth hormone treatment. However, growth hormone is a potent stimulus of gluconeogenesis and an antagonist for hepatic insulin actions. Hence, an increase in hepatic glucose production and consequent underestimation of glucose rate of disappearance might be expected to occur after, rather than before growth hormone-treatment, so we have no reason to believe that this issue biased our results.

In conclusion, we have shown that long-term, low-dose growth hormone administration improves insulin sensitivity, preserves beta cell function and improves post-load glucose tolerance without modifying body composition, lipolysis and insulin clearance. Our data imply that low-dose growth hormone is possibly the optimal replacement dose to reduce type 2 diabetes risk in adults with severe growth hormone deficiency and concomitant glucose intolerance. However, the mechanisms underlying these effects are still not fully understood, so further investigation is necessary.

Acknowledgements We thank B. Saller for his support. We also thank K. Sprengel, B. Braedigkeit and P. Exner for excellent technical assistance. This work was supported by a research grant from Pfizer Inc. (NRA 6280012). J. Spranger and M. Möhlig were supported by a graduate school (GK1208) and J. Spranger by a HeisenbergProfessorship (SP716/2-1) of the German Research Foundation. M. O. Weickert (BMBF 0313826A) and A. F. H. Pfeiffer (BMBF 0313042) were supported by grants of the German Federal Ministry of Education and Research.

Duality of interest The authors declare that there is no duality of interest associated with this manuscript.

\section{References}

1. Simpson H, Savine R, Sonksen P et al (2002) Growth hormone replacement therapy for adults: into the new millennium. Growth Horm IGF Res 12:1-33

2. Tomlinson JW, Holden N, Hills RK et al (2001) Association between premature mortality and hypopituitarism. West Midlands Prospective Hypopituitary Study Group. Lancet 357:425-431

3. Erfurth EM, Bulow B, Eskilsson J, Hagmar L (1999) High incidence of cardiovascular disease and increased prevalence of cardiovascular risk factors in women with hypopituitarism not receiving growth hormone treatment: preliminary results. Growth Horm IGF Res 9(Suppl A):21-24

4. Rosenfalck AM, Fisker S, Hilsted J et al (1999) The effect of the deterioration of insulin sensitivity on beta-cell function in growthhormone-deficient adults following 4-month growth hormone replacement therapy. Growth Horm IGF Res 9:96-105

5. Weaver JU, Monson JP, Noonan K et al (1995) The effect of low dose recombinant human growth hormone replacement on regional fat distribution, insulin sensitivity, and cardiovascular risk factors in hypopituitary adults. J Clin Endocrinol Metab 80: 153-159

6. Yuen K, Cook D, Ong K et al (2002) The metabolic effects of short-term administration of physiological vs high doses of GH therapy in GH deficient adults. Clin Endocrinol (Oxf) 57: $333-341$
7. Yuen KC, Dunger DB (2007) Therapeutic aspects of growth hormone and insulin-like growth factor-I treatment on visceral fat and insulin sensitivity in adults. Diabetes Obes Metab 9:11-22

8. O'Neal DN, Kalfas A, Dunning PL et al (1994) The effect of 3 months of recombinant human growth hormone $(\mathrm{GH})$ therapy on insulin and glucose-mediated glucose disposal and insulin secretion in GH-deficient adults: a minimal model analysis. J Clin Endocrinol Metab 79:975-983

9. Arwert LI, Roos JC, Lips P, Twisk JW, Manoliu RA, Drent ML (2005) Effects of 10 years of growth hormone $(\mathrm{GH})$ replacement therapy in adult GH-deficient men. Clin Endocrinol (Oxf) 63:310 316

10. Hana V, Silha JV, Justova V, Lacinova Z, Stepan JJ, Murphy LJ (2004) The effects of GH replacement in adult GH-deficient patients: changes in body composition without concomitant changes in the adipokines and insulin resistance. Clin Endocrinol (Oxf) 60:442-450

11. Bulow B, Erfurth EM (1999) A low individualized GH dose in young patients with childhood onset GH deficiency normalized serum IGF-I without significant deterioration in glucose tolerance. Clin Endocrinol (Oxf) 50:45-55

12. Yuen KC, Frystyk J, White DK et al (2005) Improvement in insulin sensitivity without concomitant changes in body composition and cardiovascular risk markers following fixed administration of a very low growth hormone $(\mathrm{GH})$ dose in adults with severe GH deficiency. Clin Endocrinol (Oxf) 63:428-436

13. Yuen KC, Dunger DB (2006) Persisting effects on fasting glucose levels and insulin sensitivity after 6 months of discontinuation of a very low-dose GH therapy in adults with severe GH deficiency. Clin Endocrinol (Oxf) 64:549-555

14. Boguszewski CL, Meister LH, Zaninelli DC, Radominski RB (2005) One year of GH replacement therapy with a fixed low-dose regimen improves body composition, bone mineral density and lipid profile of GH-deficient adults. Eur J Endocrinol 152:67-75

15. Hugl SR, White MF, Rhodes CJ (1998) Insulin-like growth factor I (IGF-I)-stimulated pancreatic beta-cell growth is glucosedependent. Synergistic activation of insulin receptor substratemediated signal transduction pathways by glucose and IGF-I in INS-1 cells. J Biol Chem 273:17771-17779

16. Rhodes CJ (2000) IGF-I and GH post-receptor signaling mechanisms for pancreatic beta-cell replication. J Mol Endocrinol 24:303-311

17. Kulkarni RN, Holzenberger M, Shih DQ et al (2002) Beta-cellspecific deletion of the Igfl receptor leads to hyperinsulinemia and glucose intolerance but does not alter beta-cell mass. Nat Genet 31:111-115

18. Xuan S, Kitamura T, Nakae J et al (2002) Defective insulin secretion in pancreatic beta cells lacking type 1 IGF receptor. J Clin Invest 110:1011-1019

19. Liu W, Chin-Chance C, Lee EJ, Lowe WL Jr (2002) Activation of phosphatidylinositol 3-kinase contributes to insulin-like growth factor I-mediated inhibition of pancreatic beta-cell death. Endocrinology 143:3802-3812

20. Ahren B, Thorsson O (2003) Increased insulin sensitivity is associated with reduced insulin and glucagon secretion and increased insulin clearance in man. J Clin Endocrinol Metab 88:1264-1270

21. Yuen K, Wareham N, Frystyk J et al (2004) Short-term low-dose growth hormone administration in subjects with impaired glucose tolerance and the metabolic syndrome: effects on beta-cell function and post-load glucose tolerance. Eur J Endocrinol 151: $39-45$

22. Acerini CL, Cheetham TD, Edge JA, Dunger DB (2000) Both insulin sensitivity and insulin clearance in children and young adults with type I (insulin-dependent) diabetes vary with growth hormone concentrations and with age. Diabetologia 43:61-68 
23. Lucidi P, Lauteri M, Laureti S et al (1998) A dose-response study of growth hormone $(\mathrm{GH})$ replacement on whole body protein and lipid kinetics in GH-deficient adults. J Clin Endocrinol Metab 83:353-357

24. Fowelin J, Attvall S, Lager I, Bengtsson BA (1993) Effects of treatment with recombinant human growth hormone on insulin sensitivity and glucose metabolism in adults with growth hormone deficiency. Metabolism 42:1443-1447

25. Diamond MP, Simonson DC, DeFronzo RA (1989) Menstrual cyclicity has a profound effect on glucose homeostasis. Fertil Steril 52:204-208

26. Haffner SM, Karhapaa P, Mykkanen L, Laakso M (1994) Insulin resistance, body fat distribution, and sex hormones in men. Diabetes 43:212-219

27. Arafat AM, Mohlig M, Weickert MO et al (2008) Growth hormone response during oral glucose tolerance test: the impact of assay method on the estimation of reference values in patients with acromegaly and in healthy controls, and the role of gender, age, and body mass index. J Clin Endocrinol Metab 93:1254-1262

28. Arafat AM, Weickert MO, Frystyk J, et al (2009) The role of insulin-like growth factor (IGF) binding protein-2 in the insulinmediated decrease in IGF-I bioactivity. J Clin Endocrinol Metab 94:5093-5101

29. DeFronzo RA, Tobin JD, Andres R (1979) Glucose clamp technique: a method for quantifying insulin secretion and resistance. Am J Physiol 237:E214-E223

30. Veening MA, van Weissenbruch MM, Heine RJ, Delemarre-van de Waal HA (2003) Beta-cell capacity and insulin sensitivity in prepubertal children born small for gestational age: influence of body size during childhood. Diabetes 52:1756-1760

31. Elmlinger MW, Kuhnel W, Weber MM, Ranke MB (2004) Reference ranges for two automated chemiluminescent assays for serum insulin-like growth factor I (IGF-I) and IGF-binding protein 3 (IGFBP-3). Clin Chem Lab Med 42:654-664

32. Polonsky KS, Rubenstein AH (1984) C-peptide as a measure of the secretion and hepatic extraction of insulin. Pitfalls and limitations. Diabetes 33:486-494

33. Polonsky KS, Given BD, Hirsch L et al (1988) Quantitative study of insulin secretion and clearance in normal and obese subjects. J Clin Invest 81:435-441

34. Mittelman SD, Van Citters GW, Kim SP et al (2000) Longitudinal compensation for fat-induced insulin resistance includes reduced insulin clearance and enhanced beta-cell response. Diabetes 49:2116-2125

35. Alberti KGM, Zimmet P, Shaw J (2005) The metabolic syndromea new worldwide definition. The Lancet 366:1059-1062

36. Bramnert M, Segerlantz M, Laurila E, Daugaard JR, Manhem P, Groop L (2003) Growth hormone replacement therapy induces insulin resistance by activating the glucose-fatty acid cycle. J Clin Endocrinol Metab 88:1455-1463

37. Hansen TK, Gravholt CH, Orskov H, Rasmussen MH, Christiansen JS, Jorgensen JO (2002) Dose dependency of the pharmacokinetics and acute lipolytic actions of growth hormone. J Clin Endocrinol Metab 87:4691-4698

38. Biasotti A, Houssay BA (1932) Phlorrhizin diabetes in fasting or fed hypophysectomized dogs. J Physiol 77:81-91

39. Rizza RA, Mandarino LJ, Gerich JE (1982) Effects of growth hormone on insulin action in man. Mechanisms of insulin resistance, impaired suppression of glucose production, and impaired stimulation of glucose utilization. Diabetes 31:663-669

40. Nielsen S, Moller N, Christiansen JS, Jorgensen JO (2001) Pharmacological antilipolysis restores insulin sensitivity during growth hormone exposure. Diabetes 50:2301-2308

41. Segerlantz M, Bramnert M, Manhem P, Laurila E, Groop LC (2001) Inhibition of the rise in FFA by Acipimox partially prevents $\mathrm{GH}$-induced insulin resistance in $\mathrm{GH}$-deficient adults. J Clin Endocrinol Metab 86:5813-5818

42. Yuen K, Ong K, Husbands S et al (2002) The effects of short-term administration of two low doses vs the standard GH replacement dose on insulin sensitivity and fasting glucose levels in young healthy adults. J Clin Endocrinol Metab 87:1989-1995

43. Plockinger U, Reuter $T$ (2008) Pegvisomant increases intraabdominal fat in patients with acromegaly: a pilot study. Eur J Endocrinol 158:467-471

44. Davidson MB (1987) Effect of growth hormone on carbohydrate and lipid metabolism. Endocr Rev 8:115-131

45. Press M (1988) Growth hormone and metabolism. Diabetes Metab Rev 4:391-414

46. Yuen KC, Dunger DB (2006) Impact of treatment with recombinant human GH and IGF-I on visceral adipose tissue and glucose homeostasis in adults. Growth Horm IGF Res 16(Suppl A):S55-S61

47. Pierluissi J, Campbell J (1980) Metasomatotrophic diabetes and its induction: basal insulin secretion and insulin release responses to glucose, glucagon, arginine and meals. Diabetologia 18:223228

48. Wiesli P, Schaffler E, Seifert B, Schmid C, Donath MY (2004) Islets secretory capacity determines glucose homoeostasis in the face of insulin resistance. Swiss Med Wkly 134:559-564

49. Beshyah SA, Henderson A, Niththyananthan R et al (1995) The effects of short and long-term growth hormone replacement therapy in hypopituitary adults on lipid metabolism and carbohydrate tolerance. J Clin Endocrinol Metab 80:356-363

50. Hother-Nielsen O, Henriksen JE, Holst JJ, Beck-Nielsen H (1996) Effects of insulin on glucose turnover rates in vivo: isotope dilution vs constant specific activity technique. Metabolism 45:82-91 